\title{
ATOMIC FORCE MICROSCOPY OF TORUS-BEARING PIT MEMBRANES
}

\author{
Roland R. Dute ${ }^{1, *}$ and Thomas Elder ${ }^{2}$
}

\begin{abstract}
SUMMARY
Atomic force microscopy was used to compare the structures of dried, torus-bearing pit membranes from four woody species, three angiosperms and one gymnosperm. Tori of Osmanthus armatus are bipartite consisting of a pustular zone overlying parallel sets of microfibrils that form a peripheral corona. Microfibrils of the corona form radial spokes as they traverse the margo. Margo microfibrils are loosely packed thus facilitating passage of water molecules. The pustular layer is removed by acidified sodium chlorite. Tori of Cercocarpus montanus also have a pustular surface, but lack a corona. Tori of Pinus taeda have a finely granular to amorphous torus matrix. Ulmus alata tori have microfibrils traversing the surface. The atomic force microscope proves itself a useful tool for high resolution study of pit membranes with only minimal specimen preparation.
\end{abstract}

Key words: AFM, atomic force microscope, Cercocarpus, Osmanthus, Pinus, Ulmus, pit membrane, torus.

\section{INTRODUCTION}

Tori are centrally located thickenings found on intervascular pit membranes. Along with their associated apertures, tori serve as a mechanism to impede spread of air embolisms (Zimmermann 1983). Tori are traditionally associated with wood of conifers, Ginkgo and Ephedra (Bauch et al. 1972). Recently, they have also been found in some species of Gnetum (Carlquist \& Robinson 1995). It was assumed for many years that tori were absent from intervascular pit membranes of angiosperms until Ohtani and Ishida (1978) discovered them in the wood of three species of Osmanthus and three species of Daphne. The number of woody dicotyledons now known to possess tori totals over eighty species within thirteen genera and five families (Dute et al. 2010a; Dute et al. 2011). Distribution, morphology and ontogeny of these structures have been described using light microscopy, scanning electron microscopy (SEM) and transmission electron microscopy (TEM). Torus studies have proven useful in clarifying the systematics of the Oleaceae (Dute et al. 2008b; Rabaey et al. 2008; Dute et al. 2010b).

1) Department of Biological Sciences, Auburn University, Life Sciences Building, Auburn, Alabama 36849-5407, U.S.A.

2) USDA-Forest Service, Southern Research Station, 2500 Shreveport Highway, Pineville, Louisiana 71360, U.S.A.

*) To whom correspondence should be addressed [E-mail: duterol@auburn.edu]. 
The atomic force microscope (AFM) represents a relatively new type of imaging device (Binning et al. 1986). In the microscope's "tapping" mode, a stylus mounted on a cantilever arm comes into repeated contact with the specimen's surface. The resulting loss of oscillation amplitude is used to manufacture an image (Kirby et al. 1995). The microscope provides atomic level resolution (Hanley et al. 1992). This resolution can be used to its fullest advantage because the specimen need not be coated with metal (Kirby et al. 1995). Also, specimens do not need to be processed to withstand a vacuum and, in some cases, can be observed in a hydrated state (Bezanilla et al. 1994; Kirby et al. 1995, 1996; Pesacreta et al. 2005).

AFM was used early on to characterize cellulose microfibrils in walls of the green alga Valonia (Hanley et al. 1992; Kuutti et al. 1995). These studies were followed by investigation of cellulose microfibrils from parenchyma cell wall material (Kirby et al. 1996; Thimm et al. 2000) and from plant cell trichomes (cotton fibers - Pesacreta et al. 1997). Marga et al. (2005) used AFM to investigate the response of cellulose microfibrils to cell elongation.

Only one instance is known of AFM being used to study pit membranes. Pesacreta et al. (2005) published an AFM study of pit membranes of Sapium sebiferum, a nontorus-bearing species. The present manuscript characterizes pit membranes from woods of Pinus taeda, Ulmus alata, Cercocarpus montanus, and Osmanthus armatus with an emphasis on the latter species. All four species have torus-bearing pit membranes (Thomas 1968; Dute et al. 2010a \& b). Results of this study are compared with results of comparable studies of the same genera or species using SEM and TEM.

\section{MATERIALS AND METHODS}

Six specimens of Osmanthus armatus (toothed sweet olive) were purchased from Cistus Nursery (Sauvie Island, Oregon, U.S.A.), repotted in Baccto Premium Potting Soil (Michigan Peat Company, Houston, Texas, U.S.A.), and kept in a greenhouse on the campus of Louisiana State University-Alexandria where they were watered daily. Branch specimens of Ulmus alata were obtained from a living tree at the Donald E. Davis Arboretum in Auburn, Alabama. Branch specimens of Pinus taeda came from specimens growing in Pineville, Louisiana. Branch segments from Ulmus and Pinus were split lengthwise and air-dried in an oven at $55^{\circ} \mathrm{C}$ for two days before viewing with the AFM. Samples of Cercocarpus branches were removed from herbarium specimens used in a previous study (AUA 48029 - C. montanus; AUA $67303-$ C. betuloides; Dute et al. 2010a). Cercocarpus betuloides is a synonym for C. montanus (Dute et al. 2010a).

Samples of Osmanthus armatus were viewed with the AFM either after air-drying or after chemical treatment. A number of procedures for air-drying were tried but the one giving the best results involved removal of bark from $3 \mathrm{~mm}$ long branch segments and air-drying in a $55^{\circ} \mathrm{C}$ oven for 1-7 days. Dried specimens were split longitudinally through the pith and mounted, split surface upward, in a droplet of fingernail polish on a metallic stub. Solvent-drying involved dehydrating fresh specimens in an ethanol series and replacing the ethanol with HMDS (Nation 1983). Some specimens were air-dried 
directly from absolute alcohol. Air-dried specimens of Ulmus, Pinus and Cercocarpus were mounted for AFM viewing in the same manner as Osmanthus.

Removal of incrusting materials from tori of $O$. armatus specimens involved a basic procedure using acidified sodium chlorite (Thomas 1968). Basically, this procedure required immersion of the specimens in increasing concentrations of sodium chlorite solution of increasing acidity for a period of hours followed by dehydration and HMDS treatment.

Attempts at visualizing hydrated pit membranes proved unsuccessful.

Atomic force microscopy was carried out with a Dimension 3100 Scanning Probe Microscope using the tapping mode. Samples were imaged using TAP150 tips. Images were captured at $512 \times 512$ resolution. The amplitude set point was approximately $1.8 \mathrm{~V}$. Height, amplitude and phase images were saved on a Nanoscope 5.31r1 software program.

\section{RESULTS}

Figures 1-4 show comparative AFM images (scale bar $=1 \mu \mathrm{m}$ for all) of air-dried, intervascular pit membranes from four different species: Osmanthus armatus Diels, Pinus taeda L., Ulmus alata Michx. and Cercocarpus montanus Raf. Even a cursory glance shows considerable differences in pit membrane size, in torus structure and in arrangement of margo microfibrils among the species.

Abbreviations used in the figures in this study: $A=$ annulus; $C=$ corona; $C R=$ crystals; $\mathrm{M}=$ margo; $\mathrm{P}=$ pustules; $\mathrm{R}=$ circular ring of microfibrils; $\mathrm{T}=$ torus; $\mathrm{W}=$ warts.

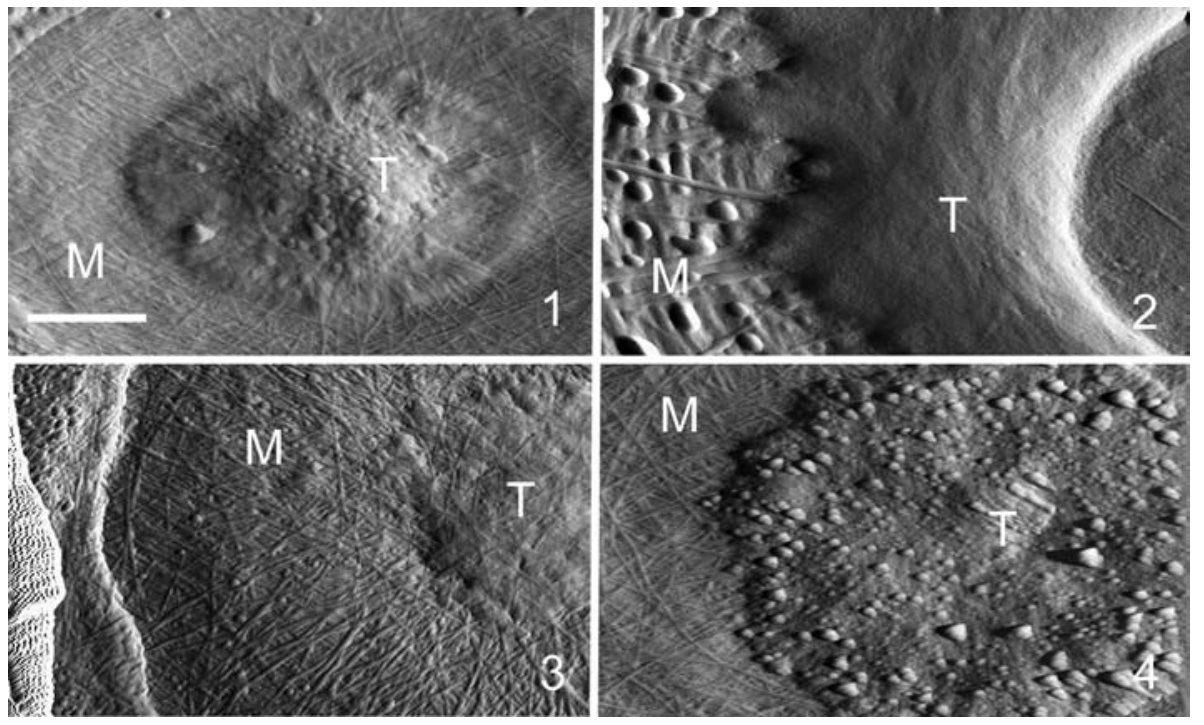

Figure 1-4. Torus-bearing pit membranes of Osmanthus armatus (Fig. 1), Pinus taeda (Fig. 2), Ulmus alata (Fig. 3) and Cercocarpus montanus (Fig. 4) imaged to the same scale. Clearly, tori are of different construction among the four species. Notable is a pustular region surrounded by a corona of microfibrils in the torus of $O$. armatus. - Scale bar $=1 \mu \mathrm{m}$ for Fig. $1-4$. 

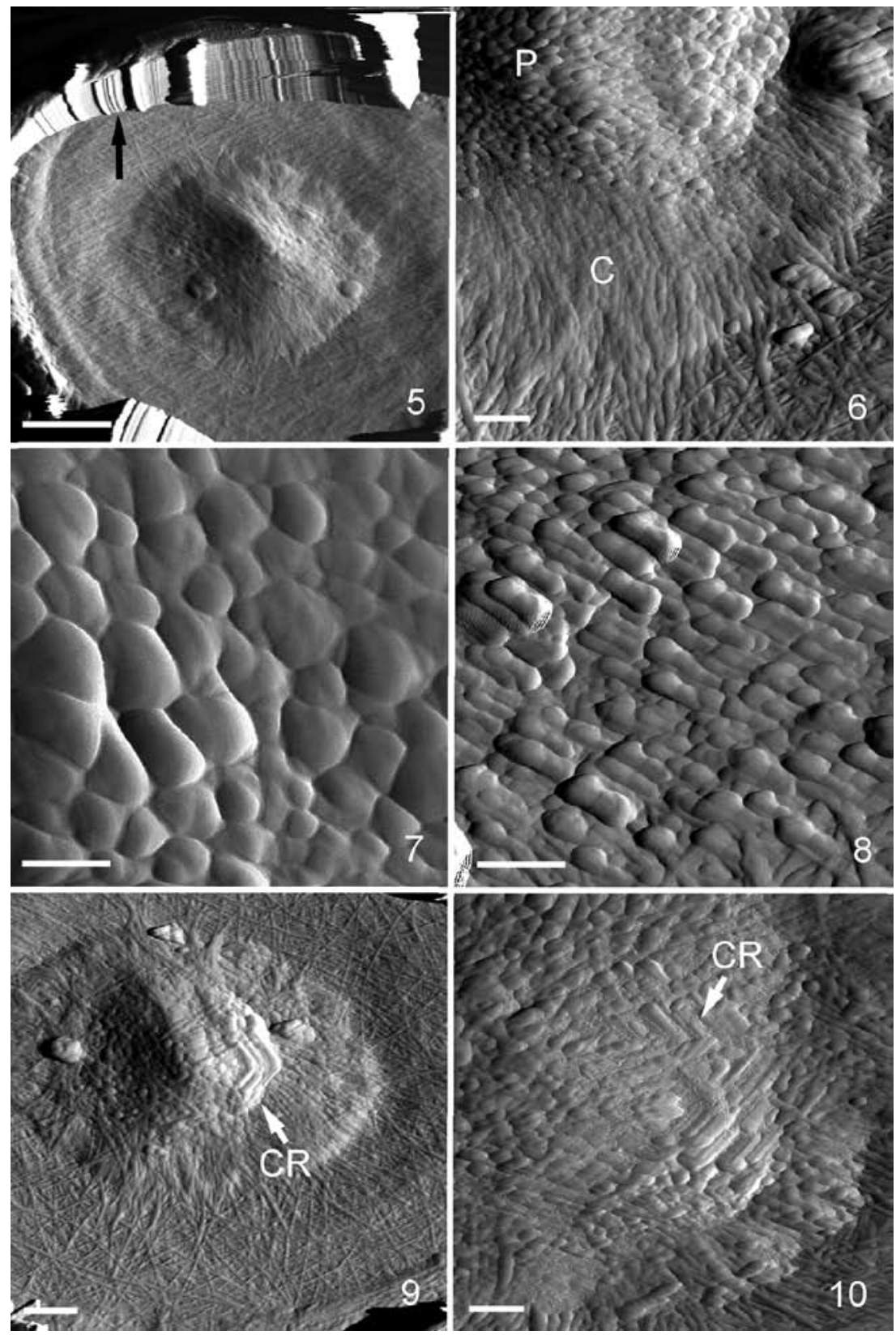

Figure 5-10. Tori of Osmanthus armatus. All images represent amplitude mode. - 5: Air-dried pit membrane of $O$. armatus in which the overarching pit border is only partly removed (arrow). - 6: Air-dried pit membrane showing the contrast between pustular surface and corona. - 7: Detail of pustules. - 8: Solvent-dried torus with pustules elongated and aligned in rows. $-9-10$ : Tori containing stacked crystalloids. - Scale bars $=1 \mu \mathrm{m}$ for Fig. 5; $0.25 \mu \mathrm{m}$ for Fig. $6 \& 10 ; 0.1 \mu \mathrm{m}$ for Fig. 7; $0.2 \mu \mathrm{m}$ for Fig. 8; $0.5 \mu \mathrm{m}$ for Fig. 9 . 


\section{Osmanthus}

Emphasis in this manuscript is placed on intervascular pit membranes of Osmanthus armatus and what follows is a description of these membranes. Membranes will be identified as "air-dried" or "solvent (HMDS)-dried" if a distinction is called for. In the former the mean maximum displacement of the margo from the plane of the annulus was $353.39 \mathrm{~nm}(\mathrm{~N}=12)$, whereas in the latter it was only $11.52 \mathrm{~nm}(\mathrm{~N}=10)$. Thus, solvent drying was successful in reducing pit aspiration.

Figure 5 shows a pit membrane subtending a partially removed pit border. Such instances proved difficult to scan, sometimes resulting in damage to the probe.

Pustular region - With the AFM the torus of $O$. armatus resolves itself into two regions: the central pustular region and the surrounding corona or fringe (Fig. $1 \& 6$ ).

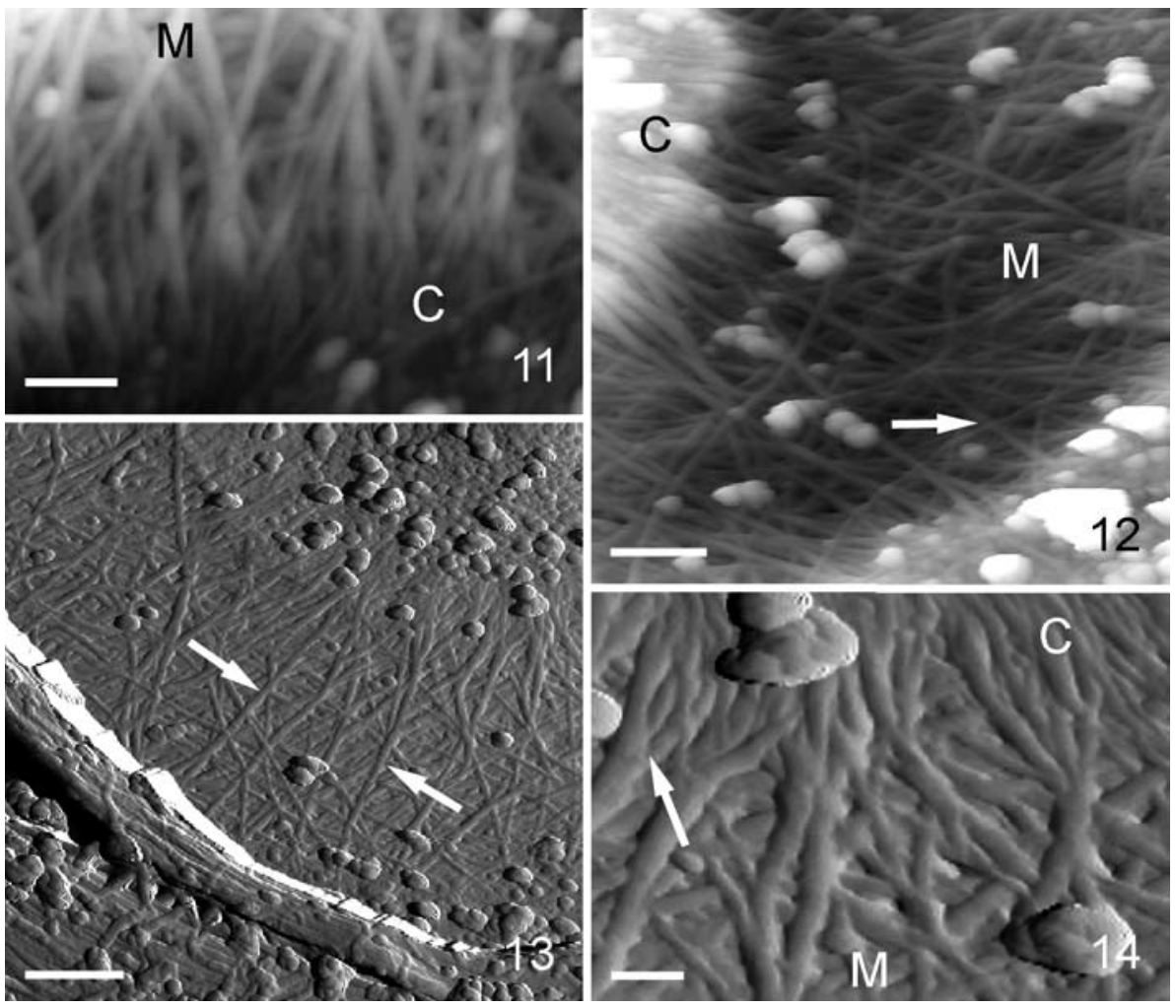

Figure 11-14. Microfibrils of corona and margo in pit membranes of Osmanthus armatus. 11: Microfibrils exiting corona and entering margo. The microfibrils are in multiple layers. Height mode. - 12: Microfibrils traversing corona and entering margo. The corona is brighter than the margo indicating its greater height. Corona microfibrils extending into the margo are covered by later deposited microfibrils (arrow). Height mode. - 13: Solvent-treated pit membrane. Some microfibrils pass directly over the surface of the margo in a radial fashion (arrows). Amplitude mode. -14 : Detail of corona/margo boundary showing corona microfibrils fusing as they enter the margo (arrow). Solvent-dried, amplitude mode. - Scale bars $=0.15 \mu \mathrm{m}$ for Fig. 11; $0.25 \mu \mathrm{m}$ for Fig. 12; $0.5 \mu \mathrm{m}$ for Fig. 13; $0.1 \mu \mathrm{m}$ for Fig. 14. 
Pustules on a given torus surface vary in diameter (Fig. 7). Detailed views often show individual pustules to consist of fused elements (Fig. 7). Also, pustules can be deposited atop other pustules. In many pit membranes there is a ridge or circular projection which occupies most of the pustular region (Fig. 5). It is not uncommon to find radial rows of pustules situated over subtending microfibrils (Fig. 8). Pustules can be difficult to distinguish from debris. Generally, pustules are uncommon in the corona and margo in air-dried specimens. Large, compound pustules are more common on the torus surface of solvent-dried pit membranes as well as on the surface of the margos and might represent debris.

Examples were found of crystalloid structures in tori of air-dried pit membranes. One example also was observed in a torus of an ethanol-dried membrane (Fig. 9). These crystalloids are superimposed in offset stacks. Individual crystalloid planes may be embedded within the pustular region of the torus or lie on its surface. Some views indicate the crystalloids to be modified pustules (Fig. 10). Phase images show no differences in hardness between pustules and crystalloids.

Corona (fringe) - Emerging from beneath the pustules is a ring of tightly packed, radiating microfibrils forming a corona (Fig. $1 \&$ 6). Height images (Fig. 11) show the corona to consist of more than one layer of microfibrils. In some specimens, the corona gradually appears out of the pustular region as beaded fibrils and becomes more distinct at the torus rim (Fig. 6).

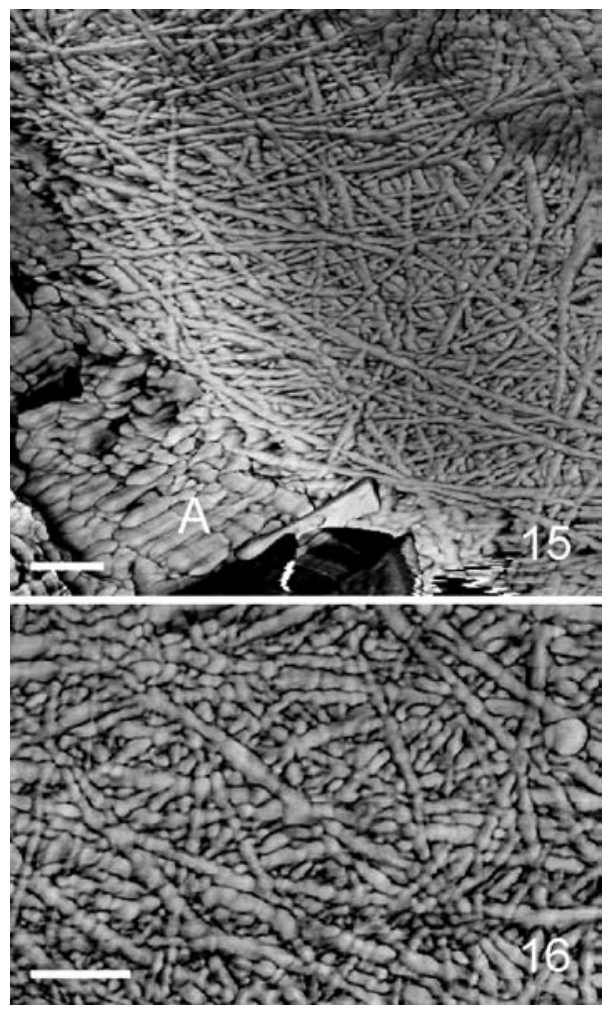

The ratio of corona diameter to that of the pustular region varies from one pit membrane to the next. Also, the radius of the corona can vary around the corona's circumference.

There is a distinct drop off (in height) at the boundary where corona meets margo, even in HMDS-treated specimens (Fig. 12). Some corona fibrils pass directly over the surface of the margo (Fig. 13). These particular fibrils give the radial component to the margo. Other corona fibrils either seemingly terminate at the boundary or pass into the margo but are covered and hidden by later-deposited margo microfibrils. It is difficult

Figure $15 \& 16$. Phase images of the pit membrane margo in Osmanthus armatus. 15:A typical margo showing microfibrils in various orientations. The annulus is indicated. - 16: Detail of the margo in an air-dried pit membrane showing the microfibrils with a beaded appearance. - Scale bars $=0.25$ $\mu \mathrm{m}$ for both figures. 
to say which hypothesis is correct. Clearly, some corona fibrils are overlain by other microfibrils within the margo (Fig. 12). Certain specimens show corona microfibrils entering the margo to be thicker than the other margo microfibrils. Some corona fibrils split as they enter the margo, whereas others fuse (Fig. 14).

Margo - Much of the margo consists of overlapping microfibrils (Fig. 15). Height images show there to be considerable space around the microfibrils in both air-dried and solvent-dried (Fig. 12) pit membranes. Microfibrils in air-dried pit membranes have something of a beaded appearance (Fig. 16).

Annulus - Pit membranes of $O$. armatus are circumscribed by an annulus. The annulus is frequently concealed by remnants of the pit border and can not be visualized by the AFM. When visible, the annulus varies in structure but often consists of parallel rows of elements. Each element consists of square to rectangular subunits (Fig. 15).

Removal of incrustives - Sodium chlorite treatment removes variable amounts of the pustular surface from the torus. Even in the most thoroughly treated specimens, some small pustules often remain amongst the exposed microfibrils (Fig. $17 \& 18$ ). It appears as if the pustules exist not only on the surface but also within the torus.

Removal of the pustules exposes the fibrillar component in the center of the torus. The fibrils have a beaded substructure (Fig. 18), traverse the diameter of the torus, and are clearly one and the same as the corona microfibrils (Fig. 19). Parallel sets of microfibrils oriented in different directions are placed one atop another (Fig. 19).

Figure 17-19. Sodium chlorite-treated tori of Osmanthus armatus pit membranes. Amplitude mode. - 17: Most pustules have been removed and the subtending microfibrils exposed. - 18: Microfibrils with beaded appearance exposed by removal of the pustules. - 19: Layers of microfibrils with different orientations exposed by removal of torus pustules. - Scale bars $=0.5 \mu \mathrm{m}$ for all figures.
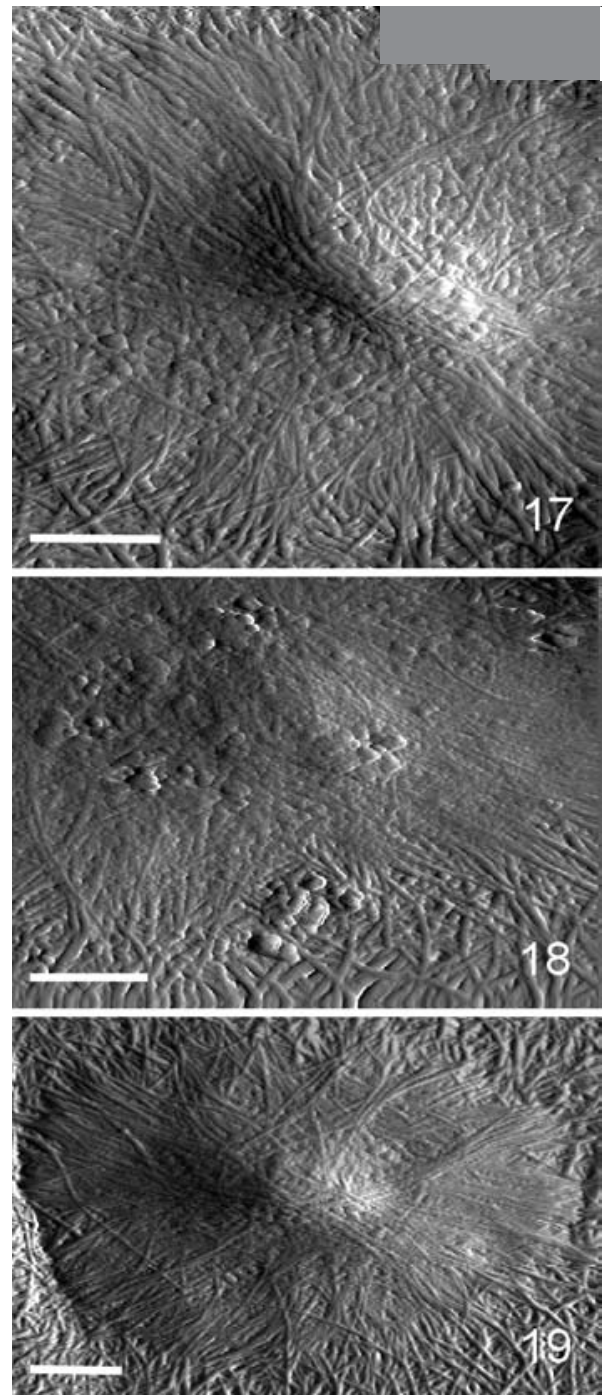

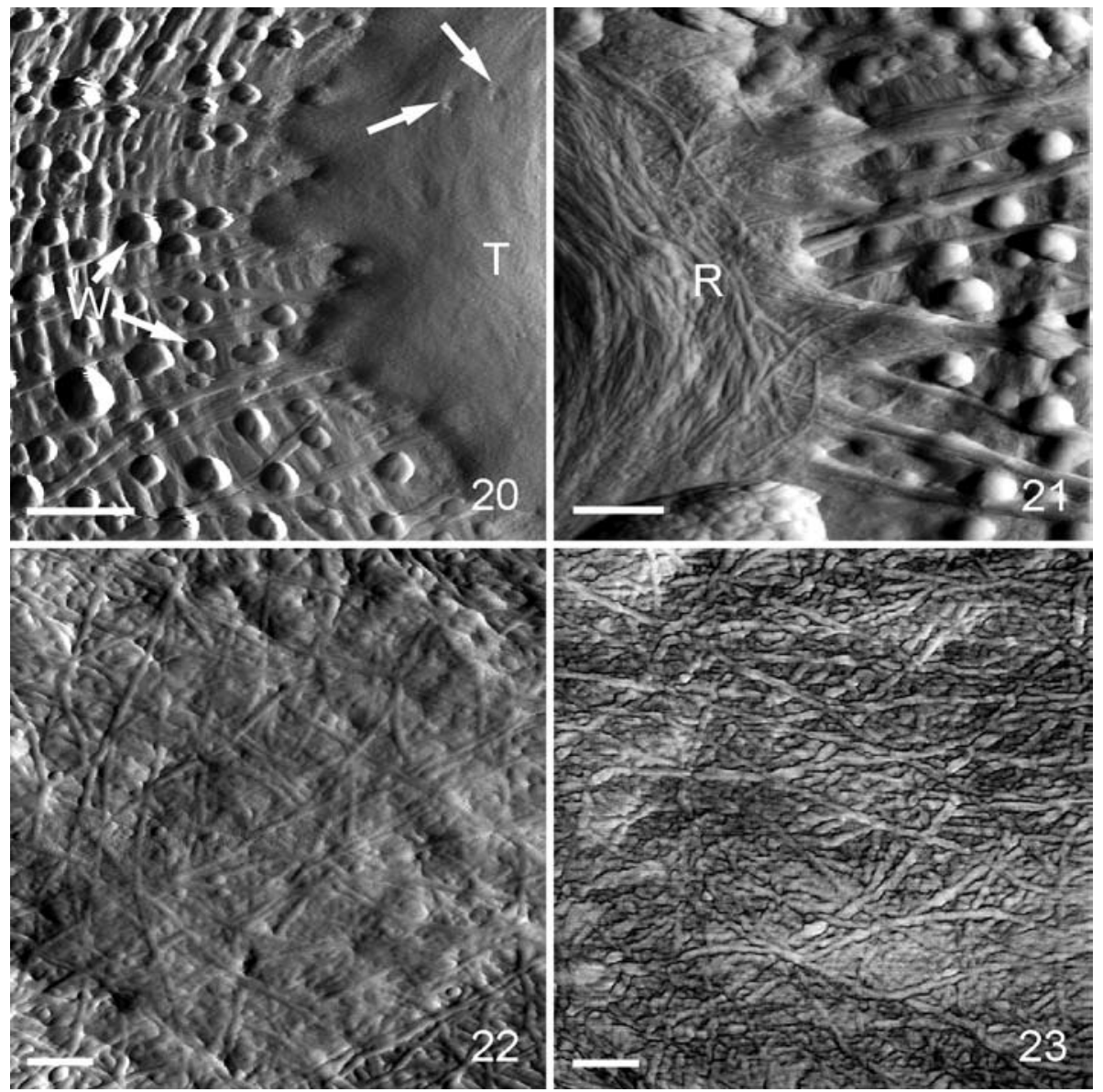

Figure 20-23. Air-dried pit membranes of Pinus taeda and Ulmus alata. - 20: Torus/margo border in P. taeda. Unlabeled arrows indicate possible plasmodesmata in the torus. Numerous warts attached to the pit border are evident. Amplitude mode. -21 : Periphery of a pine torus showing a circular ring of microfibrils. Amplitude mode. - 22: Torus of U. alata with microfibrils randomly traversing the surface. Note subtending matrix material. Amplitude mode. 23: Detail of surface microfibrils of elm torus. Phase mode. - Scale bars $=1 \mu \mathrm{m}$ for Fig. 20; $0.5 \mu \mathrm{m}$ for Fig. $21 ; 0.25 \mu \mathrm{m}$ for both Fig. $22 \& 23$.

Figure 24-29. Air-dried pit membranes of Cercocarpus montanus (Fig. 24-27) and images of pit borders (Fig. $28 \& 29$ ). - 24: Overall view of pit membrane of $C$. montanus. The torus has pustules on its surface but no corona. Amplitude mode. - 25: Detail of the torus showing pustules of varying diameter. Phase mode. - 26: Detail of torus surface. Larger pustules consist of subunits. Amplitude mode. - 27: Torus/margo border. Some radial microfibrils are present (arrows), but the margo consists primarily of microfibrils proceeding in various directions. Phase mode. - 28: Portion of a pit border in a specimen of Osmanthus armatus treated with sodium chlorite. Note the distinct concentric microfibrils (asterisk) in the pit border. Ampli- 

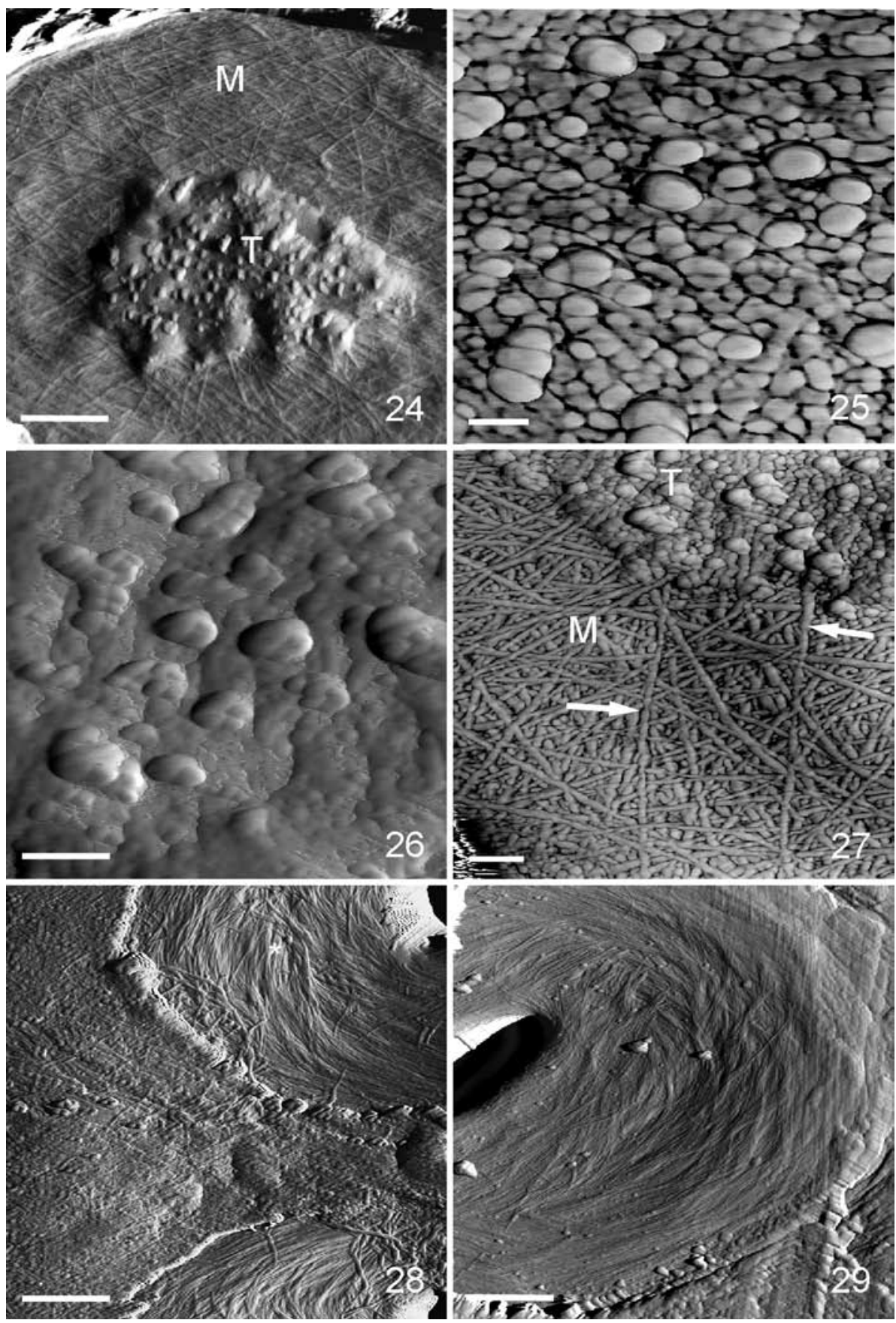

tude mode. - 29: Pit border (not treated with sodium chlorite) from $O$. armatus. Concentric microfibrils are present but are less distinct than in the previous figure. Amplitude mode. - Scale bars $=1 \mu \mathrm{m}$ for Fig. 24, $28 \&$ 29; $0.1 \mu \mathrm{m}$ for Fig. 25; $0.2 \mu \mathrm{m}$ for Fig. 26; $0.25 \mu \mathrm{m}$ for Fig. 27. 


\section{Pinus}

Tori of Osmanthus armatus show an interesting set of characters. To see how widespread such a morphology might be, tori from air-dried pit membranes of Pinus taeda, Ulmus alata and Cercocarpus montanus were observed by AFM.

Pine tori have an irregular margin (Fig. 2). The torus center is depressed and occludes the aperture. The torus matrix is finely granular (Fig. 20). Microfibrils within the matrix vary in their visibility from one torus to the next. Particularly noticeable are the circular oriented microfibrils, which are located just beyond the depressed center of the torus (Fig. 21). Possible plasmodesmatal remnants also exist (Fig. 20).

Distinct microfibrils radiate from the torus across the margo (Fig. 2). Some of these microfibrils emerge from the torus in clusters (Fig. $20 \& 21$ ). Such microfibrils can be so tightly juxtaposed that only careful observation can distinguish individual strands. Some microfibrils extend to the edge of the pit membrane, others do not. Perhaps in the latter situation, microfibrils break during aspiration or sectioning with the razor blade.

\section{Ulmus}

The torus in the latewood of Ulmus alata is a circular structure with scalloped edges (Fig. 3 \& 22). Its most distinctive feature, and the one that sets it apart from tori of Pinus and Osmanthus, is the presence of microfibrils crossing its surface (Fig. 22). Detailed views show microfibrils of both torus and margo to possess a beaded appearance (Fig. 23). In Fig. 22 the microfibrils appear to be less distinct as they cross the torus perhaps due to a thin matrix coating. Microfibrils of other Ulmus tori are much more distinct.

Some microfibrils are continuous from the margo across the surface of the torus, whereas others enter the interior of the torus and disappear (Fig. 22). This does not mean that the latter are not continuous across the pit membrane. As noted by Wheeler (1983), there is a distinct radial orientation to many of the microfibrils of the margo (Fig. 3). The radial microfibrils are at the surface of the margo.

\section{Cercocarpus}

The torus in Cercocarpus pit membranes varies in outline from circular to irregular (Fig. 4 \& 24). As in Osmanthus, the torus surface of Cercocarpus is covered with pustules of varying diameter (Fig. 4). Phase images of the surface show that rather than sitting on the surface, the pustules are actually anchored within the torus (Fig. 25). Detailed views show the larger, emergent pustules to consist of subunits (Fig. 25 \& 26). In some instances pustules form parallel rows. Larger pustules extend some distance above the surface of the torus, giving the surface a coarser appearance compared with that of Osmanthus (compare Fig. 4 \& 1).

A notable difference between tori of Osmanthus and Cercocarpus is the absence of a corona in the latter. Radial microfibrils do emerge from the torus, but they are not organized into a corona (Fig. 27). These radial microfibrils traverse the surface of the margo for the most part (Fig. 27), indicating that they are deposited later in pit membrane development.

The "woven" nature of the microfibrils of the margo is obvious (Fig. 27). The fact that the torus thickening sits atop the microfibrils (Fig. 27) indicates that the formation of the torus is the end point of pit membrane ontogeny. 


\section{Pit border}

The pit border surface facing the pit membrane consists of concentric microfibrils in all species studied (Fig. 28). Sodium chlorite treatment produces pit borders with more distinct microfibrils (Fig. 28 vs. 29).

\section{DISCUSSION}

\section{AFM}

Jansen et al. (2008) examined the effects of preparative techniques on the structure of pit membranes. Some morphology-altering processes such as sputter-coating and the heat of an electron beam are avoided through the use of AFM. However, AFM is not without its difficulties. The topographic extremes encountered, especially if remnants of the pit border are present (Fig. 5), can lead to tip damage. Also, even with the locator microscope attached to the AFM system it proved very difficult to position the tip within the confines of an exposed pit membrane. Nevertheless, the ease of preparation and the resolution provided by the AFM more than compensate for these drawbacks.

\section{Osmanthus}

Discovery of torus-bearing membranes in Osmanthus recently has been documented by Dute et al. (2010 b). In short, tori were first observed in intravascular pit membranes of Osmanthus fragrans, O. heterophyllus and O. fortunei (Ohtani \& Ishida 1978). With that beginning, the number of torus-bearing species discovered in Osmanthus now stands at 14 . This list includes $O$. armatus in which tori were reported in the 2010 survey. The two species of the related genus Picconia also possess tori (Dute et al. 2008 b; Rabaey et al. 2008) as does one species of Chionanthus, also a close relative in the Oleaceae (Rabaey et al. 2008). Not surprisingly, an SEM image of a P. excelsa pit membrane appears to show a torus with both pustule region and corona (Rabaey et al. 2008, fig. 10). This observation requires confirmation.

The original publication by Ohtani and Ishida (1978), while brief, is comprehensive. They used material that was alcohol-fixed and solvent-dried. Material was viewed either with a field emission SEM or with a TEM using the carbon replica technique. They observed both random and radially oriented microfibrils in the margo. The authors noted the removal of the "amorphous substances" from the torus through use of sodium chlorite with the resulting exposure of parallel arrays of microfibrils extending in different directions. A diagram of the microfibillar arrangement was presented in a later article (Ohtani 1983). It was felt that the overlapping arrays of fibrils resulted in the torus thickening. Since $O$. armatus is found within the same section of the genus as the species used by Ohtani and Ishida (Xiang et al. 2008), it is not surprising that our observations correspond with theirs.

Ohtani and Ishida (1978) noted in their study only that "the torus (was) incrusted with amorphous substances" but did not describe the pustular surface nor distinguish this surface from the encircling corona. Clearly, the pustular surface represents the last phase of torus construction. This layer corresponds to the deposit that stains bluegreen with $\mathrm{TBO}$ in $O$. armatus (Dute, unpublished results) and reacts with $\mathrm{KMnO}_{4}$ in O. americanus (Coleman et al. 2004). These so-called "torus pads" in O. armatus thus 
are at least partially lignified (Coleman et al. 2004-in contrast to the compound middle lamella that they cover) and are responsible, in addition to the overlapping arrays of microfibrils, for the thickening of the torus. Interestingly, small amounts of lignin have been discovered in non-torus-bearing intervascular pit membranes of the dicotyledons Rhizophora mucronata and Avicennia marina (Schmitz et al. 2008).

Pustules were previously observed using SEM on the tori of air-dried membranes of Osmanthus americanus by Dute and Rushing (1987) and on various Osmanthus species by Dute et al. (2010 b). However, not much thought was given to the situation because the resolution was inadequate. With the resolution provided by the AFM and with the presence of pustules in both air-dried and solvent-dried preparations, we are inclined to view these structures as real. However, to confirm this supposition will require AFM imaging of fresh specimens.

Deposition of torus pads occurs late in cell ontogeny and is associated with dictyosome vesicles and a plexus of microtubules (Dute \& Rushing 1988). It is tempting to associate each pustule with the contents of a single vesicle, but this hypothesis is probably naïve.

Torus crystalloids in Osmanthus are an unusual feature. The term refers to the regular, repeated substructures observed. They do not in any way appear to be related to typical calcium oxalate crystals found in plant cells, although EDX-analysis is required to confirm this supposition. The function of these structures is unknown. Another example of crystalline structures in xylem cells of Osmanthus was found in the nuclei (Dute \& Rushing 1988). One could speculate that with the breakdown of the nucleus, crystalloids were deposited on the torus, but the embedded nature of many crystalloids within the torus makes this scenario unlikely.

The height image of the AFM provides a major advantage in that it gives a detailed, three-dimensional picture of the pit membrane. In doing so, it shows a considerable amount of space surrounding the microfibrils of the margo and confirms that water molecules have distinct, if convoluted, pathways from one cell to the next.

The present investigation is restricted to dried pit membranes, but observation of hydrated pit membranes is essential for an understanding of their functional structure and for an understanding of those changes occurring during the process of air drying. For example, Pesacreta et al. (2005) observed irregular regions of non-microfibrillar material on the pit membrane surface of air-dried Sapium wood. In hydrated specimens, the non-microfibrillar layer covered the entire surface of the pit membrane. Preliminary observations show irregular regions of non-microfibrillar material on the surface of Osmanthus armatus (as well as Cercocarpus montanus and Ulmus alata) pit membranes (data not shown). These observations need to be confirmed in air-dried material and compared with the situation in hydrated pit membranes from the same species.

\section{Pinus}

Anatomical features observed by AFM in pine pit membranes are similar to those observed with SEM or TEM for many other conifers, for example, radial microfibrils in the margo (Bauch et al. 1972), plasmodesmata in the torus, and concentric microfibrils in the torus of the Pinaceae (Liese 1965; Parham \& Baird 1973; Dute et al. 2008a). 
Distribution, development, and possible function of plasmodesmata in pit membranes of conifers and Ginkgo have been discussed at some length (Murmanis \& Sachs 1969; Thomas 1969, 1972; Fengel 1972; Fujikawa \& Ishida 1972; Barnett \& Harris 1975; Timell 1979; Dute 1994; Dute et al. 2008a). In contrast, plasmodesmata are largely absent from intervascular pit membranes of woody dicotyledons (Barnett 1982).

In contrast to Osmanthus armatus, the torus surface matrix of Pinus is finely granular rather than pustular at the magnifications used. This difference in texture correlates with wall chemistry in that investigators have found a high concentration of pectin rather than lignin in the tori of conifers (Bauch et al. 1968; Bauch \& Berndt 1973; Thomas 1975; Tschernitz \& Sachs 1975).

\section{Ulmus}

Wheeler (1983) was the first to describe torus-bearing pit membranes between vascular tracheids of two species of Ulmus, including U. alata. She used carbon replicas of either air-dried or solvent-dried material and viewed the replicas with a transmission electron microscope. She observed not only the torus, but also noted radial microfibrils in the margo as well as microfibrils apparent on the torus surface. Tori with irregular margins and with surface microfibrils were observed also in Ulmus americana by Jansen et al. (2007, q.v. their Fig. 14) using field emission scanning electron microscopy. Thus, prior observations have been confirmed via the AFM.

Wheeler (1983) noted in U. alata that because "microfibrils are distinct in this central thickened region ... thickening is not due to the accumulation of encrusting materials." This hypothesis was supported by work of Dute and Rushing (1990) in which torus thickenings in Ulmus and Celtis consisted of primary wall material deposited at an early stage of pit membrane ontogeny. A later study (Coleman et al. 2004) showed evidence for partial autolysis of torus material associated with a possible absence of lignification in $U$. alata and $C$. occidentalis. Thus, the torus material observed in the present study represents residual matrix material from the compound middle lamella of the pit membrane not removed during cellular autolysis. The microfibrils that we observed on the surface of the mature torus in the present study probably represented microfibrils exposed by the removal of matrix material during ontogeny. Partial matrix removal would also explain the irregular torus margin.

In addition to ring-porous species of Ulmus (Jansen et al. 2004), tori also are present in the related genera Celtis (Wheeler 1983), Zelkova (Jansen et al. 2004) and Planera (Dute et al. 2004; Jansen et al. 2007). TEM studies of Celtis (Dute \& Rushing 1990; Coleman et al. 2004) and Planera (Dute et al. 2004) indicate a similar torus structure and development among the genera.

\section{Cercocarpus}

There are four species of Cercocarpus all of which possess tori (Jansen et al. 2007). Although the ontogeny of torus-bearing pit membranes in Cercocarpus has been studied in sectional view via TEM (Dute et al.2010a), little has been done regarding detailed pit membrane morphology.

No plasmodesmata were observed in tori of Cercocarpus in this study, whereas they were observed only in rare instances in a previous investigation (Dute et al. 2010a). 
A comparison of torus surfaces of Osmanthus and Cercocarpus shows both to have pustules or coarse granules, although the morphologies differ (Fig. 1, 4). In contrast, torus surfaces of Pinus appear finely granular or smooth at the same magnification (Fig. 2).Pit membranes of the former two genera share a similar ontogeny in that torus deposition does not begin until the corresponding pit border is complete or nearly so (Dute \& Rushing 1988; Dute et al. 2010a). Pit membranes of conifers (Thomas 1972; Imamura \& Harada 1973) initiate torus thickening before manufacture of the pit border. Thus the type of torus surface correlates with time of synthesis.

\section{Pit border}

The presence of concentric microfibrils is common to both hardwood and softwood species and was observed using transmission electron microscopy as early as 1965 (Harada 1965 a, 1965 b; Liese 1965; Schmid 1965).

\section{ACKNOWLEDGEMENTS}

We thank Auburn University for providing sabbatical funding to the senior author and Dr. Elizabeth Elder for providing greenhouse space at Louisiana State University at Alexandria. Thanks also to Dr. Thomas Pesacreta for his willingness to aid our attempts at visualization of hydrated membranes.

\section{REFERENCES}

Barnett, J.R. 1982. Plasmodesmata and pit development in secondary xylem elements. Planta 155: 251-260.

Barnett, J.R. \& J.M. Harris. 1975. Early stages of bordered pit formation in radiata pine. Wood Sci. Technol. 9: 233-241.

Bauch, J. \& H. Berndt. 1973. Variability of the chemical composition of pit membranes in bordered pits of gymnosperms. Wood Sci. Technol. 7: 6-19.

Bauch, J., W. Liese \& F. Scholz. 1968. Über die Entwicklung and stoffliche Zusammensetzung der Hoftüpfelmembranen von Längstracheiden in Coniferen. Holzforschung 22: 144-153.

Bauch, J., W. Liese \& R. Schultze. 1972. The morphological variability of the bordered pit membranes in gymnosperms. Wood Sci. Technol. 6: 165-184.

Bezanilla, M., B. Drake, E. Nudler, M. Kashlev, P.K. Hansma \& H.G. Hansma. 1994. Motion and enzymatic degradation of DNA in the atomic force microscope. Biophys. J. 67: $2454-2459$.

Binning, G., C.F. Quate \& C.H. Gerber. 1986. Atomic force microscope. Physical Review Letters 56: 930-933.

Carlquist, S. \& A.A. Robinson. 1995. Wood and bark anatomy of the African species of Gnetum. Bot. J. Linn. Soc. 118: 123-137.

Coleman, C.M., B.L. Prather, M.J. Valente, R.R. Dute \& M.E. Miller. 2004. Torus lignification in hardwoods. IAWA Bull. n.s. 25: 435-447.

Dute, R.R. 1994. Pit membrane structure and development in Ginkgo biloba. IAWA J. 15: $75-90$.

Dute, R.R., L. Hagler \& A. Black. 2008a. Comparative development of intertracheary pit membranes in Abies firma and Metasequoia glyptostroboides IAWA J. 29: 277-289.

Dute, R., M.D. Jandrlich, S. Thornton, N. Callahan \& C.J. Hansen. 2011. Tori in species of Diarthron, Stellera and Thymelaea (Thymelaeaceae). IAWA J. 32: 54-66.

Dute, R.R., S. Jansen, C. Holloway \& K. Paris. 2008b. Torus-bearing pit membranes in selected species of the Oleaceae. J. Ala. Acad. Sci. 79: 12-22. 
Dute, R.R., A.L. Martin \& S.Jansen. 2004. Intervascular pit membranes with tori in wood of Planera aquatica J.F. Gmel. J. Ala. Acad. Sci. 75: 7-21.

Dute, R.R., J. Patel \& S. Jansen. 2010a. Torus-bearing pit membranes in Cercocarpus. IAWA J. 31: 53-66.

Dute, R.R., D. Rabaey, J. Allison \& S. Jansen. 2010b. Torus-bearing pit membranes in species of Osmanthus. IAWA J. 31: 217-226.

Dute, R.R. \& A.E. Rushing. 1987. Pit pairs in the wood of Osmanthus americanus (Oleaceae). IAWA Bull. n.s. 8: 237-244.

Dute, R.R. \& A.E. Rushing. 1988. Notes on torus development in wood of Osmanthus americanus (L.) Benth. \& Hook. ex Gray (Oleaceae). IAWA Bull n.s. 9: 41-51.

Dute, R.R. \& A.E. Rushing 1990. Torus structure and development in the woods of Ulmus alata Michx., Celtis laevigata Willd., and Celtis occidentalis L. IAWA Bull. n.s. 11: 71-73.

Fengel, D. 1972. Structure and function of the membrane in softwood bordered pits. Holzforschung 26: 1-9.

Fujikawa, S. \& S. Ishida. 1972. Study on the pit of wood cells using scanning electron microscopy. III. Structural variation of bordered pit membrane on the radial wall between tracheids in Pinaceae species. J. Jap. Wood Res. Soc. 18: 477-483.

Hanley, S.J., J. Giasson, J.-F. Revol \& D.G. Gray. 1992. Atomic force microscopy of cellulose microfibrils: comparison with transmission electron microscopy. Polymer 33: 4639-4642.

Harada, H. 1965a. Ultrastructure and organization of gymnosperm cell walls. In: W.A. Côté, Jr. (ed.), Cellular ultrastructure of woody plants: 215-234. Syracuse University Press.

Harada, H. 1965b. Ultrastructure of angiosperm vessels and ray parenchyma. In: W.A. Côté, Jr. (ed.), Cellular ultrastructure of woody plants: 235-250. Syracuse University Press.

Imamura, Y. \& H. Harada. 1973. Electron microscopic study on the development of the bordered pit in coniferous tracheids. Wood Sci. Technol. 7: 189-205.

Jansen, S., B. Choat, S. Vinckier, F. Lens, P. Schols \& E. Smets. 2004. Intervascular pit membranes with a torus in the wood of Ulmus (Ulmaceae) and related genera. New Phytol. 163: 51-59.

Jansen, S., A. Pletsers \& Y. Sano. 2008. The effect of preparation techniques on SEM-imaging of pit membranes. IAWA J. 29: 161-178.

Jansen, S., Y. Sano, B. Choat, D. Rabaey, F. Lens \& R.R. Dute. 2007. Pit membranes in tracheary elements of Rosaceae and related families: new records of tori and pseudotori. Amer. J. Bot. 94: 503-514.

Kirby, A.R., A.P. Gunning \& V.J. Morris. 1995. Atomic force microscopy in food research: a new technique comes of age. Trends in Food Science \& Technology 6: 359-365.

Kirby, A.R., A.P. Gunning, K.W. Waldron, .J. Morris \& A. Ng. 1996. Visualization of plant cell walls by atomic force microscopy. Biophys. J. 70: 1138-1143.

Kuutti, L., J. Peltonen, J. Pere \& O. Teleman. 1995. Identification and surface structure of crystalline cellulose studied by atomic force microscopy. J. Microscopy 178: 1-6.

Liese, W. 1965. The fine structure of bordered pits in softwoods. In: W.A. Côté, Jr. (ed.), Cellular ultrastructure of woody plants: 271-290. Syracuse University Press.

Marga, F., M. Grandbois, D.J. Cosgrove \& T.I. Baskin. 2005. Cell wall extension results in the coordinate separation of parallel microfibrils: evidence from scanning electron microscopy and atomic force microscopy. Plant J. 43: 181-190.

Murmanis,L.\& I.B. \& Sachs. 1969. Seasonal development of secondary xylem in Pinus strobus L. Wood Sci. Technol. 3: 177-193.

Nation, J.L. 1983. A new method using hexamethyldisilazane for preparation of soft insect tissues for scanning electron microscopy. Stain Technol. 58: 347-351.

Ohtani, J. 1983. SEM investigation on the micromorphology of vessel wall sculptures. Res. Bull. of the College of Experiment Forests, College of Agriculture, Hokkaido University 40: $323-386$. 
Ohtani, J. \& S. Ishida. 1978. Pit membrane with torus in dicotyledonous woods. Mokuzai Gakkaishi 24: 673-675.

Parham, R.A. \& W.M. Baird. 1973. The bordered pit membrane in differentiating balsam fir. Wood \& Fiber 5: 80-86.

Pesacreta, T.C., L.C. Carlson \& B.A. Triplett. 1997. Atomic force microscopy of cotton fiber wall surfaces in air and water: quantitative and qualitative aspects. Planta 202: 435-442.

Pesacreta, T., L.H. Groom \& T.G. Rials. 2005. Atomic force microscopy of the intervessel pit membrane in the stem of Sapium sebiferum (Euphorbiaceae). IAWA J. 26: 397-426.

Rabaey, D., S. Huysmans, F. Lens, E. Smets \& S. Jansen. 2008. Micromorphology and systematic distribution of pit membrane thickenings in Oleaceae: tori and pseudo-tori. IAWA J. 29: 409-424.

Schmid, R. 1965. The fine structure of pits in hardwoods. In: W.A. Côté, Jr. (ed.), Cellular ultrastructure of woody plants: 291-304. Syracuse University Press.

Schmitz, N., G. Koch, U. Schmitt, H. Beeckman \& N. Koedam. 2008. Intervessel pit structure and histochemistry of two mangrove species as revealed by cellular UV microspectrophotometry and electron microscopy: intraspecific variation and functional significance. Microsc. Microanal. 14: 387-397.

Thimm, J.C., D.J. Burritt, W.A. Ducker \& L.D. Melton. 2000. Celery (Apium graveolens L.) parenchyma cell walls examined by atomic force microscopy: effect of dehydration on cellulose microfibrils. Planta 212: 25-32.

Thomas, R.J. 1968. The development and ultrastructure of the bordered pit membrane in southern yellow pines. Holzforschung 22: 38-44.

Thomas, R.J. 1969. The ultrastructure of southern pine bordered pit membranes as revealed by specialized drying techniques. Wood \& Fiber 1: 110-123.

Thomas, R.J. 1972. The ultrastructure of differentiating and mature bordered pit membranes from cypress (Taxodium distichum R. Rich.). Wood \& Fiber 4: 87-94.

Thomas, R.J. 1975. The effect of polyphenol extraction on enzyme degradation of bordered pit tori. Wood \& Fiber 7: 207-215.

Timell, T.E. 1979. Formation of compression wood in balsam fir (Abies balsamea). Holzforschung 33: 181-191.

Tschernitz, J.L. \& I.B. Sachs. 1975. Observations on microfibril organization of Douglas-fir bordered pit-pair membranes by scanning electron microscopy. Wood \& Fiber 6: 332-340.

Wheeler, E. A. 1983. Intervascular pit membranes in Ulmus and Celtis native to the United States. IAWA Bull n.s. 4: 79-88.

Xiang, Q., L. Liu \& X. Wu. 2008. Studies on the cultivar classification of Osmanthus. Acta Horticulturae 799: 61-65.

Zimmermann, M.H. 1983. Xylem structure and the ascent of sap. Springer, Berlin. 